\title{
Some Properties of Lightning Ground Flashes Observed in and around Sri Lanka, and their Seasonal Variations
}

\author{
J. P. Liyanage ${ }^{1}$, D. U. J. Sonnadara ${ }^{2, *}$, I. M. K. Fernando ${ }^{2}$, A. B. Weerasekera ${ }^{2}$, \\ R. Lelwala ${ }^{2}$ and T. R. Ariyaratne ${ }^{2}$ \\ ${ }^{1}$ Department of Surveying Sciences, Sabaragamuwa University of Sri Lanka, \\ Belihuloya, Sri Lanka. \\ ${ }^{2}$ Department of Physics, University of Colombo, Colombo 3, Sri Lanka.
}

\begin{abstract}
Two lightning locating systems were utilised in obtaining the cloud-to-ground flash characteristics in Sri Lanka and in the surrounding area of the Indian Ocean. Over 5,000 flashes were recorded during the year 1999 covering 39 thunder days. The lightning data are presented in terms of polarity, multiplicity, and first return stroke peak current. The percentage of positive flashes observed in this study is fairly lower than that of temporal regions but when compared with similar studies in tropical regions there is no clear difference. Out of the $3 \%$ of the positive flashes reported, $95 \%$ were single stroke. On the contrary only $56 \%$ of the reported negative flashes were single stroke. The highest percentage of single stroke negative flashes was $74 \%$ in June and lowest was $38 \%$ in February. The monthly variation of the percentage of positive flashes ranged from $17 \%$ in June to $1 \%$ in September. The highest monthly average multiplicity of negative flashes of 2.6 was recorded in February and for all other months it was below 2. The monthly averages of the negative first stroke peak currents ranged from about 39kA in August to about 56kA in September. The data obtained in the study also clearly indicates the bias in DF data for longer distances.
\end{abstract}

\section{INTRODUCTION}

It is believed that most of the lightning activities taking place on earth atmosphere is confined to tropical regions. Further more the process of thundercloud formation in tropics is different to that of temporal regions. Thus one may expect to see some differences in the characteristics of lightning flashes in the tropics than what have been reported for the temporal and sub tropical regions. When compared to the

\footnotetext{
* Corresponding author (Tel: 584777, E-mail: upul@phys.cmb.ac.lk)
} 
research studies performed on characteristics of lightning activities in temporal and sub-tropical regions, studies done in tropical countries like Sri Lanka is scared in literature ${ }^{1}$. The few studies which have been done on the characteristics of lightning flashes in Sri Lanka are confined to several isolated thunderclouds. Even these studies do not posses the valuable information such as the location of return strokes to carry out more complete analysis.

In late 1998, a lightning direction finding (DF) network was implemented in Sri Lanka to record data pertaining to cloud-to-ground (CG) lightning flashes ${ }^{1-2}$. Such networks are widely used in many countries to gather data on lightning on a continuous basis. A DF network consists of several stations each having capabilities of extracting the time of occurrence, azimuth angle, strength of the magnetic field, multiplicity (number of strokes in a flash) and polarity (negative or positive) of CG flashes by detecting the changes in the magnetic and electric fields. The operating characteristics of the DF stations have been examined and reported by many research groups $^{3-5}$ and hence details relevant only to the present analysis are discussed here.

The purpose of the work presented in this paper is to study the seasonal variations and the characteristics of CG flashes observed in Sri Lanka from the data obtained with the two station network. The results have been then compared with other measurements carried out in different geographical regions under different meteorological conditions to ascertain whether there are any marked differences.

\section{EXPERIMENTAL PROCEDURE}

The DF stations used in this work were commercially available units (LLP model DF 80-02) manufactured by the Lightning Locating and Protection (LLP) Inc., Tucson, Arizona, USA. Two DF stations were installed at Colombo (6.90N, 79.86E) and Ratnapura $(6.68 \mathrm{~N}, 80.40 \mathrm{E})$ and operated through out the year 1999 to record lightning ground flashes. Each DF station consists of a flat plate antenna to detect the changes in the electric field and a vertical, orthogonal crossed loop antenna to detect the changes in the magnetic field (See figure). Both antennas have wide bandwidths (approximately $1 \mathrm{kHz}$ to $400 \mathrm{kHz}$ ) and hence shapes and the polarities of lightning field waveforms are preserved to a large extent. The crossed loop magnetic antenna detects the two perpendicular components of the magnetic field of a lightning flash. The direction of a cloud to ground flash is obtained by using the well-known principles in radio direction finding, i.e. by calculating the ratio of the signal amplitudes on the two orthogonal loops. Processing of the detected signals are done via the electronics built into the analogue direction finder (ADF) module and the digital direction finder (DF) module. The manufacturer claims that these electronics responds only to waveforms that are characteristic of return strokes of cloud to ground flashes. A detailed account of the filtering process is given in elsewhere.

In the present set up, the output of the DF modules, which includes the time of occurrence, azimuth angle, multiplicity, polarity etc. of an identified cloud to ground 
flashes, were fed into personal computers through their serial ports and stored for offline analysis.

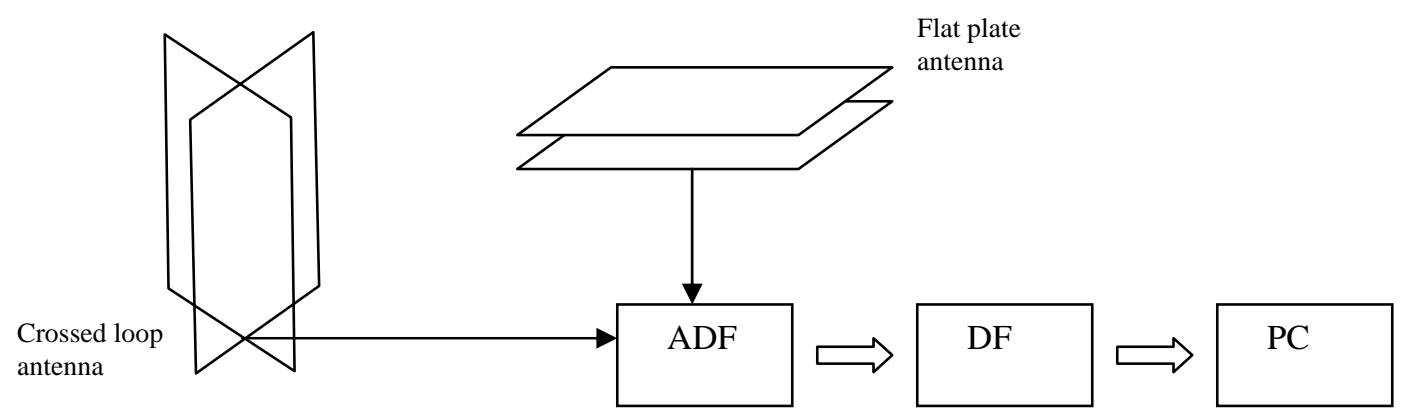

Fig.1 Schematic diagram of a DF station
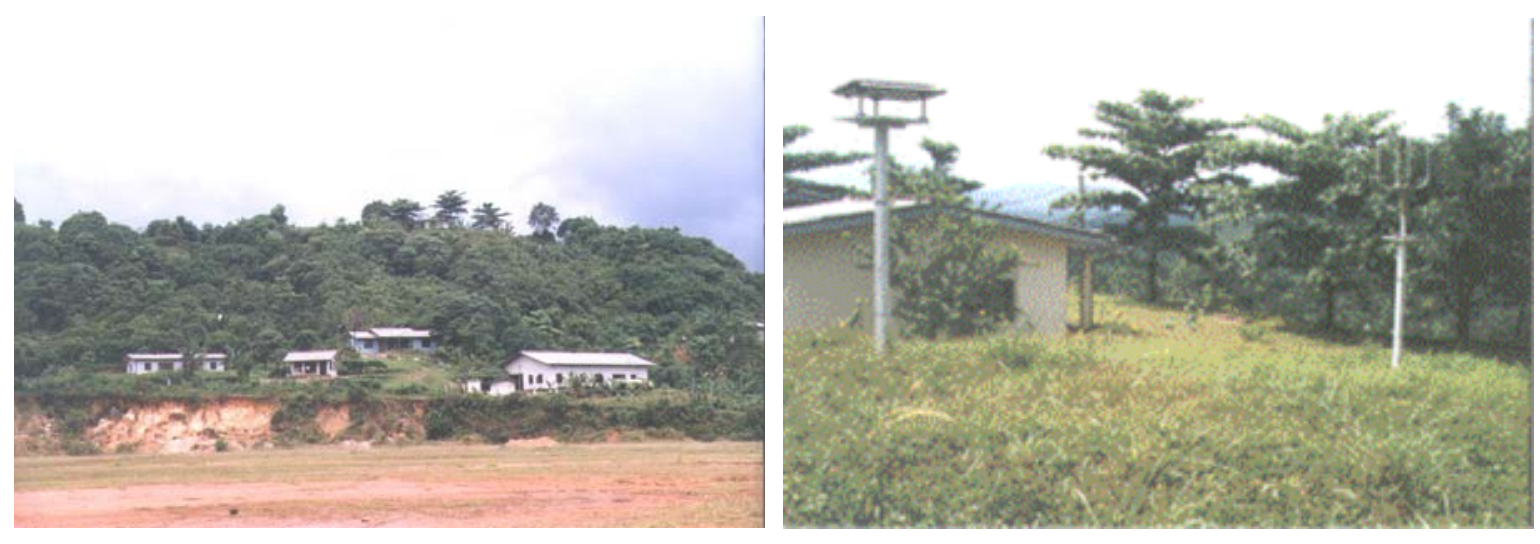

Fig. 2. DF-station at the Ratnapura Meteorology site $(6.64 \mathrm{~N}, 80.43 \mathrm{E})$. This station is located on a small hill (indicated by the circle), $86.3 \mathrm{~m}$ from sea level.

The data recorded by the two DF stations were first filtered by rejecting the signals with very low amplitude or signals that overflowed the high threshold in the DF units. In principle, both stations should receive the electromagnetic signal generated by a lighting flash almost simultaneously as the distance between the two stations can result only a negligible time jitter. Using this as the selecting criterion, the records were passed through a computer program to select simultaneous hits. A detailed description of the filtering method is given elsewhere ${ }^{1-2}$. Whenever there was a mismatch between the recorded multiplicities by the two stations, the highest multiplicity of the two was taken as the correct multiplicity, attributing the difference to either attenuation of the signal due to the distance or differed threshold settings in the two DF stations. Records, which had a mismatch in the polarity, were rejected. Then by using the angular information given by the two DF stations, the distance to the lightning strike from respective locations of the DF stations was computed. A total of 5189 cloud to ground (CG) flashes for 39 days in the months of February, May, June, August, September and October in 1999 were filtered out using this criterion. 


\section{RESULTS}

\subsection{Influence on distance}

Detection efficiency is one of the most important factors in determining the accuracy of the results obtained from a DF station. Detection efficiency is defined simply as the ratio between the number of cloud to ground flashes which was detected by a DF station to the number of cloud to ground flashes which actually occurred. This generally can be expected to be a function of the rate of occurrence of lightning and the distance to the flash. If there is a heavy lightning rate, the system may fail to record certain flashes due to the dead time of the electronics and due to extensive data processing by the electronics. The manufacturer of the DF stations claims that the dead time of the LLP DF stations is about $4 \mathrm{~ms}^{7}$. The main contribution to the dead time comes from the serial transmission of data from DF module to the computer, which takes about 250ms per flash. In average, this rate corresponds to more than 10,000 flashes per hour, which is too high to be observed in reality. Thus one can expect the lightning rate to have little influence on the detection efficiency. The distance to the location of the flash and the ground conductivity however has a considerable influence on the detection efficiency. Due to the threshold settings of the electronics, a flash having a smaller signal strength and occurring at a moderate distance may not trigger the DF unit. On the other hand a flash having a reasonable strength occurring at close distance may saturate the electronics and hence may fail to get recorded.

Maier et. al. ${ }^{7}$ has given a typical detection efficiency curve for LLP-DFs operating at medium gain based on a two station DF network in Oklahoma. According to their results a peak efficiency of about $80-90 \%$ is possible for ranges between 20 $120 \mathrm{~km}$ and efficiency drops to about $50 \%$ for distances over $350 \mathrm{~km}$. The results presented here were corrected for detection efficiency using this curve. Based on theoretical calculations Hojo et. al. ${ }^{4}$ have reported that the detection efficiency versus range have a dependency on the season (i.e. winter / summer) as well as on polarity. They assumed this is due to the change of wave form shape of electric fields in the two seasons since the cloud height is different in two seasons. However possible changes in ground conductivity in those two seasons could also be contributing to the poor detection efficiencies in winter compared to summer. This effect, however, is not taken into account in this study as the seasonal variations are not prominent in Sri Lanka.

\subsection{Percentage of positive flashes}

Since the recorded field strength and current of positive cloud-to-ground flashes are usually higher than those of the negative flashes, the former causes more damage to electrical and electronic systems as well as to property. In this study, it was 
observed that about 3\% of the observed flashes were positive cloud to ground flashes and over $95 \%$ of the positive flashes were single stroke flashes. Ninety five percent of the positive flashes being single stroke well agrees with the claim of majority being single stroke as reported by many research groups. In contrast to the high percentage of positive cloud to ground flashes observed in this study, only about $56 \%$ of the negative ones were found to be single stroke flashes.

Percentages of positive flashes observed in several studies together with the one obtained in from the present measurement are shown in table 1 . The measurements show in general that the percentage of positive flashes tends to be lower for tropical climates than for temporal regions. Particularly, in the north-eastern United States and in Japan a high percentage of positive flashes have been observed during the winter ${ }^{4}$.

Table 1. Percentage of positive flashes observed in several measurements (LPATS: Lightning positioning and tracking system, LLP - Lightning location and Protection)

\begin{tabular}{|l|l|l|l|}
\hline Location / Reference & Period & Technique & \% positive flashes \\
\hline $\begin{array}{l}\text { Tropical } \\
\text { Sri Lanka (This work) }\end{array}$ & Jan 1999- Dec 1999 & LLP & 3 \\
$\begin{array}{l}\text { Australia } \\
\text { Sub-tropical }\end{array}$ & Dec 1989-Mar 1990 & LLP & 9 \\
USA $^{12}$ & 1991 & & \\
USA $^{12}$ & $1989-1991$ & LPATS & 15 \\
USA $^{12}$ & Jun 1984-May 1985 & LLP & 4 \\
USA $^{12}$ & $1985-1986$ & LLP & 5 (summer) to 80 (winter) \\
Temporal & & 4 (Warm seasons) \\
Brazil & & \\
Japan $^{12}$ & Dec 1992-Mar 1993 & LPATS & 35 \\
Sweden $^{5}$ & $1984-1987$ & LLP ? & $5-60$ (monthly) \\
Siwitzerland & & LLP & Upto 80 \\
\hline
\end{tabular}

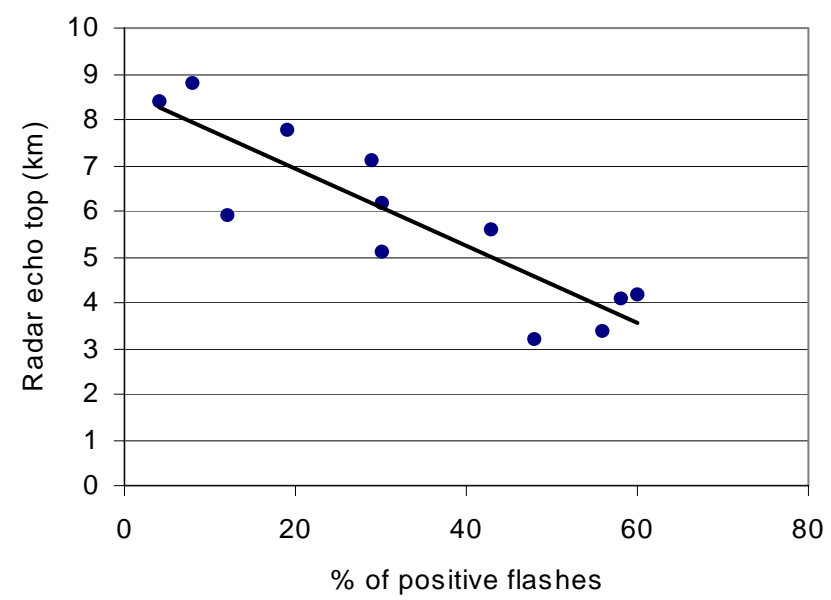

Fig. 3. The variation of percentage of positive flashes vs. the average radar echo height (data taken from reference 4) 
In figure 3, the relationship between the percentage of observed positive flashes against the radar echo height of cloud base is shown. Data was taken from reference 4. A clear negative correlation is seen between the two parameters supporting the previous observations. Hence it can be deduced from this that to observe 3\% of positive flashes, on an average the cloud base height in Sri Lanka should be about $8 \mathrm{~km}$.

\subsection{Seasonal variations}

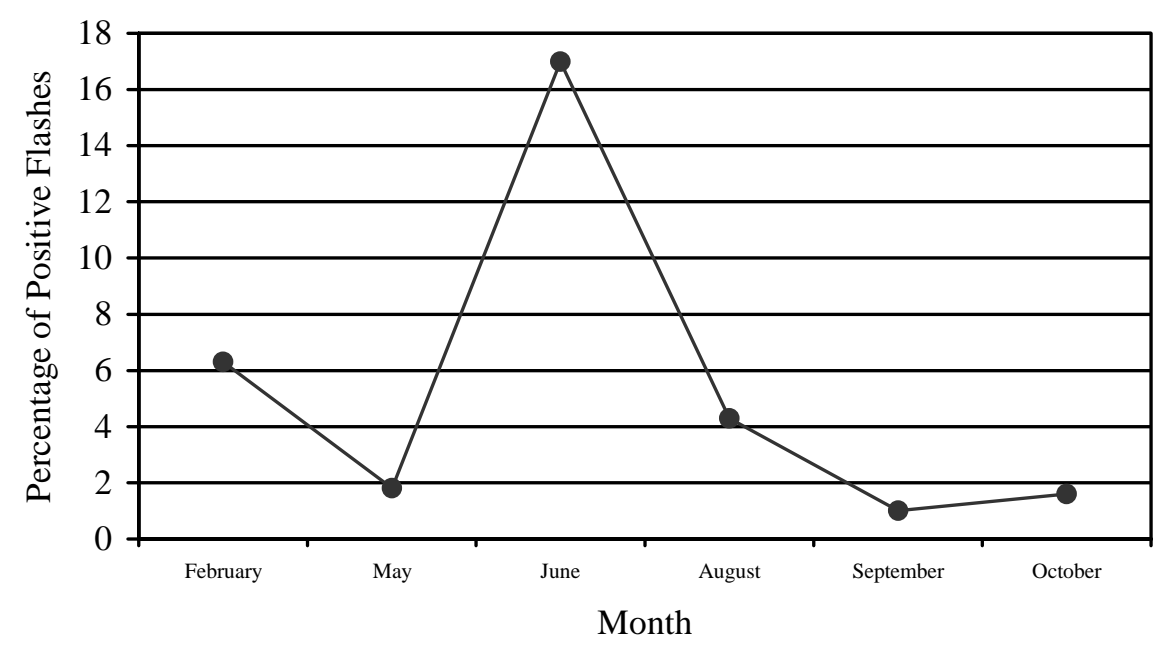

Fig. 4. Monthly variation of the ratio of the number of positive ground flashes to the total ground flashes

When seasonal variations were analysed, it was found that the percentage of positive flashes varied from $17 \%$ in June to less than $1 \%$ in September (see figure 4). As expected, the monthly variations of positive cloud to ground flash percentages for Sri Lanka are relatively low than what have been reported for Japan and Sweden. In Japan, the highest monthly percentage of positive lightning is $60 \%{ }^{4}$ while in Sweden it can go as high as $80 \%{ }^{5}$.

Figure 5 shows the average multiplicity of negative flashes. The negative cloud to ground flashes has an average multiplicity of 1.9. However this average multiplicity of negative flashes is far below the average (4.5) reported by Cooray et $a l^{3}$ who had observed waveforms of induced electric field pulses on an oscilloscope for a several thunderstorms during April 1993 in Sri Lanka. The range of the DF stations used in the present work is very high (over $400 \mathrm{~km}$ ). While gaining this advantage in coverage, the DF stations fail to record the correct multiplicity of distant flashes due to the attenuation of the signal and relatively high internal threshold settings of the DF unit. We attribute the difference to the above fact and it can be 
corrected by increasing the number of DF stations in the network so that there will be at least one DF station in close proximity to every lightning flash that strike within the region of interest.

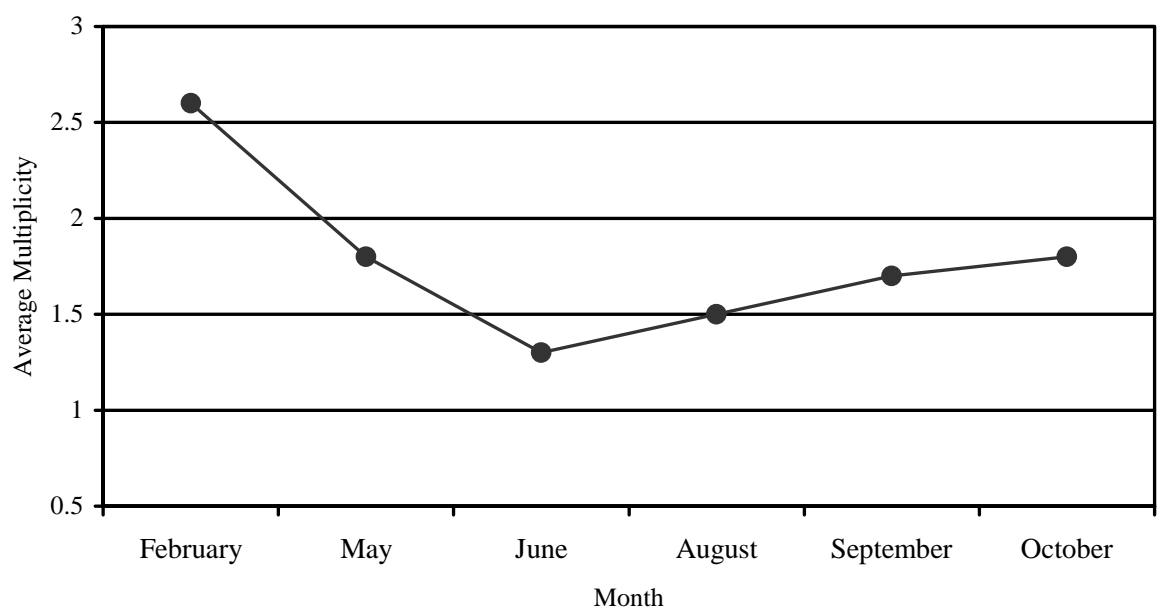

Fig. 5. Monthly variation in average multiplicity of negative flashes

It was seen that the highest average multiplicity of negative flashes was 2.6 in February and in all the other months this was below 2. The highest percentage of single stroke negative flashes was observed $74 \%$ in June and the lowest was $38 \%$ in February.

\subsection{Distribution of peak lightning currents}

The lightning signal strengths measured in 'LLP units' can be converted to peak currents by using calibrations carried out by Idone et. al. using triggered lightning events ${ }^{13,14}$. Figure 6 shows the estimated distribution of the peak current amplitudes of negative return strokes. On the same graph similar results of previously published investigations ${ }^{12}$ are also shown for comparison. All curves show a similar pattern with a peak in the 20-40kA interval.

Hojo et. al. have seen differences in the distributions of signal strengths during winter and summer seasons ${ }^{4}$. Especially for positive polarity, they have observed a larger signal strength in winter compared to the summer. Figure 7(a) shows the seasonal variation of the distribution of peak currents of observed negative CG flashes. A significant seasonal change is not visible for Sri Lanka probably due to the moderate climatic changes.

In another study ${ }^{14}$ it has been shows that depending on the distance between the lightning storm and the DF network, a bias can be introduced into the measurements due to the trigger thresholds used in the system. Especially, if the distance to the storm is large, high peak currents will be reported. Hence one has to taken into account the average distance to the storm. Figure 7(b) shows the correlation 
between the average peak current and the average distance to the storm. A clear positive correlation is seen.

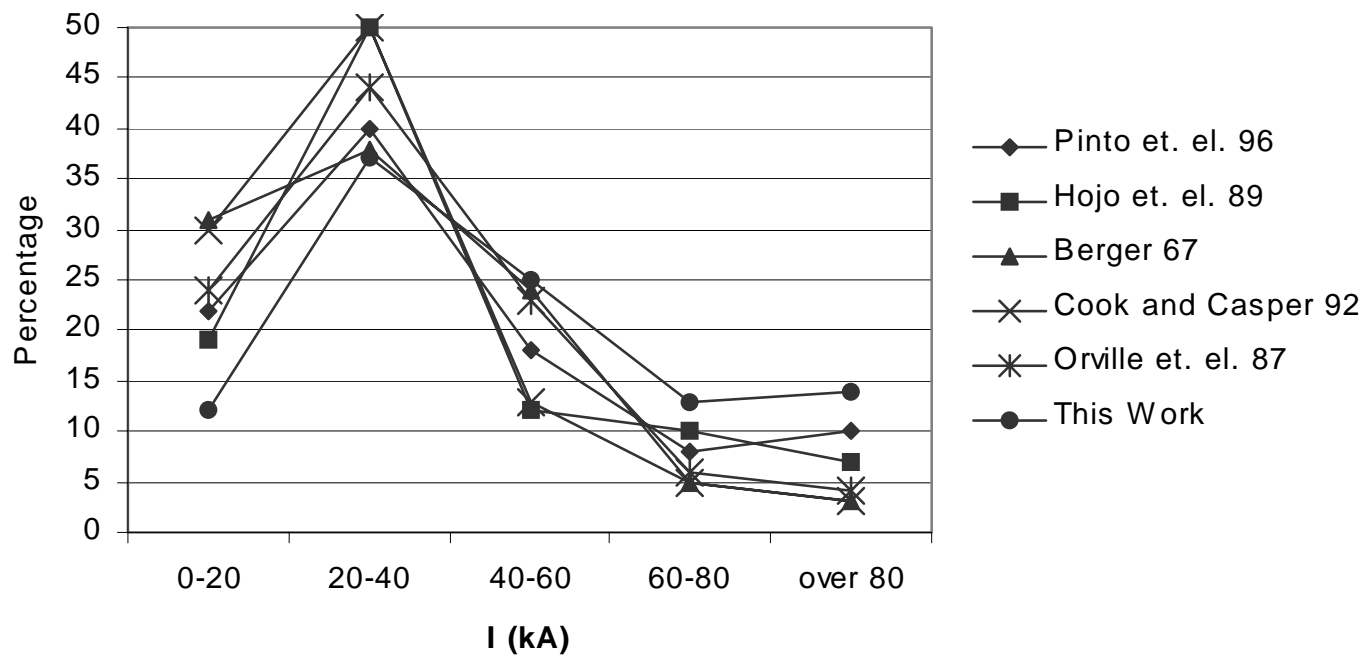

Fig.6. Distribution of peak currents for negative ground flashes

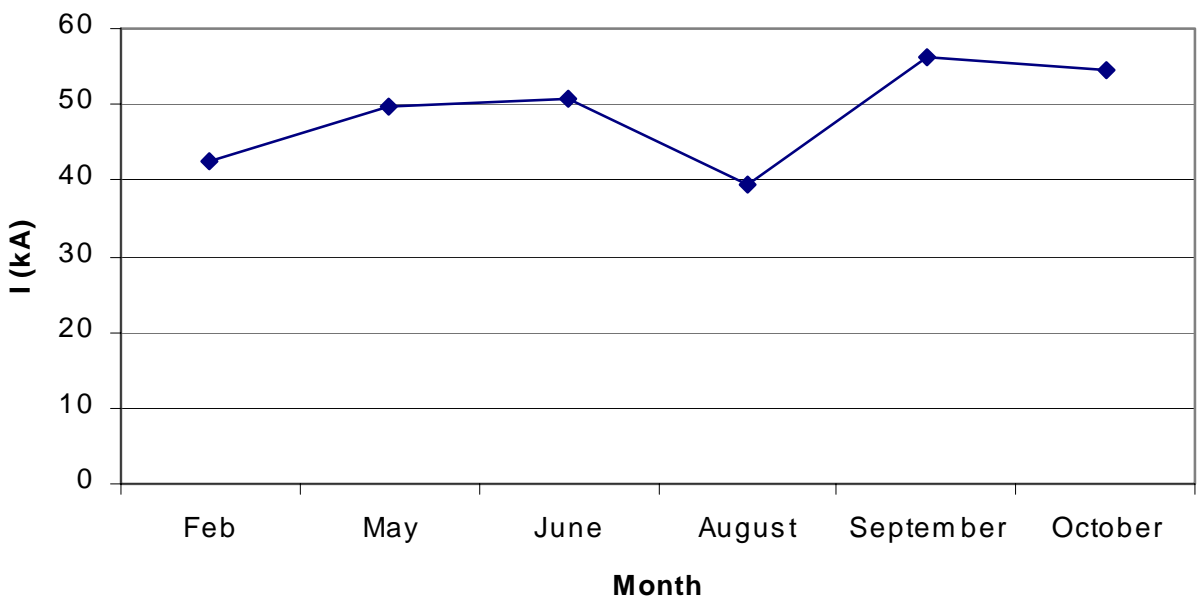




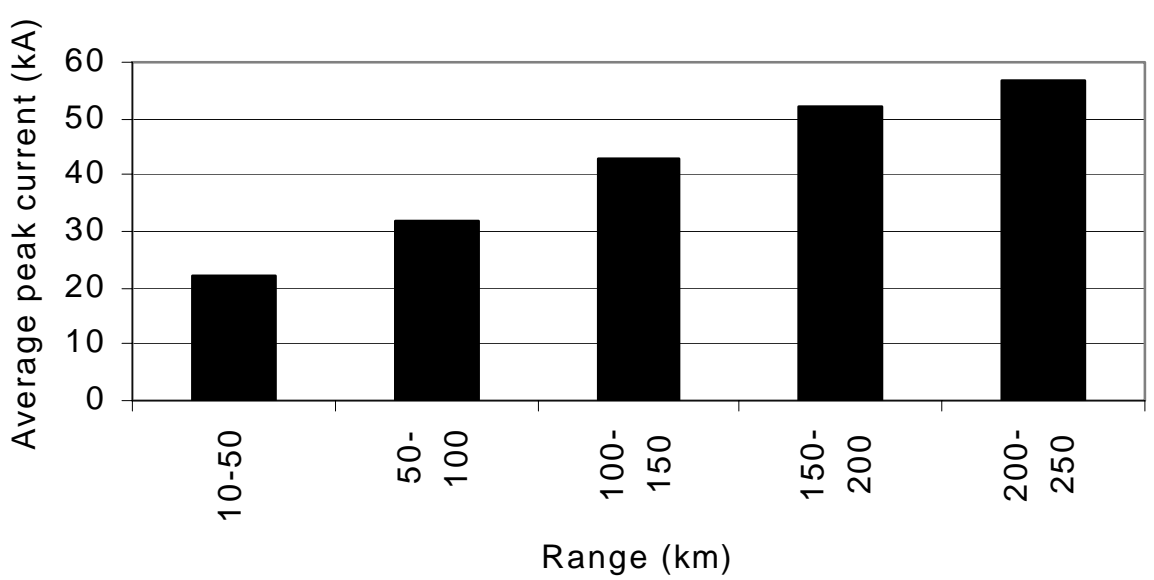

Fig. 7. (a) Monthly variation of lightning peak currents (b) peak current dependence on the distance to the storm

\subsection{Properties of isolated thunderstorms}

Four thunderstorms were isolated from the observations to study the thunderstorm characteristics in detail. Table 2 summarises the results.

Table 2: Some properties of isolated thunderstorms

\begin{tabular}{|l|l|l|l|l|l|}
\hline Thunderstorm & $\begin{array}{l}\text { Approximat } \\
\text { e Distance } \\
\text { to the storm } \\
\text { from } \\
\text { Colombo }\end{array}$ & $\begin{array}{l}\text { Average } \\
\text { flash } \\
\text { interval }\end{array}$ & $\begin{array}{l}\text { \% of } \\
\text { Positive } \\
\text { Flashes }\end{array}$ & $\begin{array}{l}\text { Average peak } \\
\text { current of } \\
\text { Negative } \\
\text { flashes }\end{array}$ & $\begin{array}{l}\text { Average } \\
\text { Multiplicity } \\
\text { of Negative } \\
\text { flashes }\end{array}$ \\
\hline Storm 1 & $30 \mathrm{~km}$ & $34 \mathrm{~s}$ & 10.3 & $11 \mathrm{kA}$ & 3.6 \\
Storm 2* & $150 \mathrm{~km}$ & $391 \mathrm{~s}$ & 2.4 & $33 \mathrm{kA}$ & 2.2 \\
Storm 3* & Over 500km & $231 \mathrm{~s}$ & 2.6 & $250 \mathrm{kA}$ & 1.7 \\
Storm 4 & $46 \mathrm{~km}$ & $37 \mathrm{~s}$ & 1.5 & $22 \mathrm{kA}$ & 2.8 \\
\hline
\end{tabular}

* storms over sea

It has been claimed that the multiplicity recorded by the DF stations are lower than the true value. Attenuation of the EM radiation when travelling long distances and hence failing to go above threshold level and trigger electronics has been sited as an explanation for it. The storm 1 is a thunderstorm that occurred very close to one DF station and thus the attenuation effects must have been at a minimum. The average multiplicity of this storm is larger than other storms which is supporting the original assumption. Figure 8 clearly indicates how multiplicity decreases with distance. A variation of the form $\mathrm{ax}^{-\mathrm{b}}$ is clearly seen. 


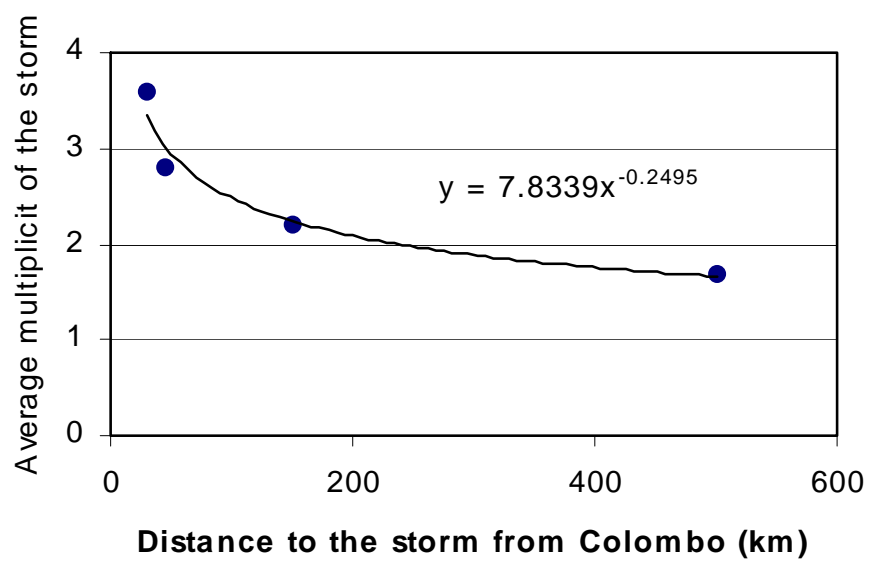

Fig..8. Variation of average multiplicity with distance for the selected storms

It can be clearly seen that the average recorded current also increases with distance. This is also in support of the conclusion drawn in 3.4. Average inter flash interval has decreased with distance. This is possible as there is a good chance to miss some flashes which are of a lower strength with increasing distance.

\section{CONCLUSIONS}

There is a considerable variation in the percentage of positive flashes by month and the majority of the positive flashes were single stroke flashes. The average multiplicity of negative flashes is lower than the values reported by Cooray et al. ${ }^{3}$ for several thunderstorms in April 1993. However, the range of the DF stations used in the present work are very high (over $400 \mathrm{~km}$ ) compared with the instruments used by them. While gaining this advantage in range, the DF stations fail to record the correct multiplicity of distant flashes due to the attenuation of the signal and high threshold settings. We attribute the difference in the results reported in the two studies to this. However, this difference can be corrected by combining sufficient number of real time data with those corresponding to DF data.

The percentage of positive flashes observed is relatively lower than the values reported in temporal regions. Out of the $3 \%$ of the positive flashes reported, $95 \%$ were single stroke. This high percentage of single stroke positive flashes well agrees with the other reported research work. However, only 56\% of the reported negative flashes were single stroke. The highest percentage of single stroke negative flashes was $74 \%$ in June and lowest was 38\% in February.

The monthly variation of the percentage of positive flashes ranged from $17 \%$ in June to $1 \%$ in September. The highest monthly average multiplicity of negative flashes of 2.6 was recorded in February and for all other months it was below 2 . 
The distribution of negative first stroke peak currents agrees well with several previously published studies. The monthly averages of the negative first stroke peak currents ranged from about 39kA in August to about 56kA in September.

Several thunderstorms were separated and analyzed in detail. This provided an opportunity to take into consideration factors such as average inter flash interval of the storm and distance to the storm. Also by selecting closer storms, a better figure for the average multiplicity of the negative flashes could be obtained. The effect of distance on the recorded average multiplicity of negative flashes, average peak currents and inter flash interval is clearly seen.

Although the network was intended to operate continuously, some technical problems prevented it being operated from round the clock. We believe this however will not affect the importance of our findings as this is the first time such data pertaining to lightning has been collected for reasonably long durations continuously.

\section{ACKNOWLEDGEMENTS}

Financial assistance by International Program for Physical Sciences, Uppsala University, Sweden (research grant number SRI:01/1), The National Science Foundation, Sri Lanka (grant number RG/99/P/02), and University of Colombo, Sri Lanka (grant number 99/S/31) are acknowledged.

\section{REFERENCES}

1. Study of the performance of direction finding stations prior to the implementation of a Lightning Location System in Sri Lanka, I.M.K. Fernando, D.U.J. Sonnadara, K.P.S.C. Jayaratne, T.R. Ariyaratne, S. Namasivayam \& K.R.A Bandara, Ceylon Journal of Science, 4, 77 (1998)

2. Locating Cloud-to-Ground lighting flashes with simultaneous two station measurements, D.U.J. Sonnadara, A.B. Weerasekera, I.M.K. Fernando, R. Lelwala, K.P.S.C. Jayaratne, T.R. Ariyaratne, S. Namasivayam \& K.R.A Bandara, Sri Lankan J. of Phys., 1 , 11 (2000)

3. Characteristics of lightning flashes observed in Sri Lanka, V. Cooray and K.P.S.C. Jayaratne, J. Geophys. Res., 99, 21051-21056 (1994).

4. Seasonal variations of cloud-to-ground lightning flash characteristics in the coastal area of the sea of Japan, J. Hojo, M. Ishii, T. Kawamura, F. Suzuki, H. Komuro, and M. Shiogama, J. of Geophysical Res. 94, 13207-13212 (1989)

5. Analysis of Swdish lightning using LLP data, Mahandra Fernando, Arturo Galvan, Thomas Gotschi, Vernon Cooray and Victor Scuka, Proc. of $24^{\text {th }}$ Internatinal Conf. on Lightning Protection, 98 (1998)

6. Lightning ground flash measurements over the contiguous United States: A ten year summary 1989-1998, Richard E. Orville, Gary Huffines, Poster

7. Locating Cloud to Ground lightning with wide band gap magnetic direction finders, M.W. Maier, R.C. Binford, L.G. Byerlay, E.P. Krider, A.E. Pifer and U.A. Uman, Fifth Symposium on Meteorological Observations and Instrumentation, Toranto, Ont., Canada April 11-15 (1983) .

8. Reexamination of the peak current calibration of the national lightning network, Vincent P. Idone , Arsalan B. Saljpoghy, Ronald W. Henderson, Paul K. Moore and Richard B. Pyle, J. Geophys. Res., $\underline{98}, 18323-18332$ (1993)

9. On the occurrence of Cloud to ground flashes in southern Sweden, S. Israelsson, E. Pisler and M.A. Enayatollah, VII International conference on Atmospheric Electricity, June 3-8 (1984)

10. Cloud to ground lightning in southeastern Brazil in 1993- Geographical distribution, O. Pinto Jr, I.R.C.A. Pinto, M.A.S.S. Gomes, I. Vitorello and A.L. Padilha, J.H. Diniz, A.M. Carvalho and A Cazetta Filho, J. Geophys. Res., 104, 31369-31379 (1999)

11. Cloud to ground lightning in southeastern Brazil in 1993- Time variation and flash characteristics, I.R.C.A. Pinto, O. Pinto Jr, R.M.L. Rocha, J.H. Diniz, A.M. Carvalho and A Cazetta Filho, J. 
Geophys. Res., 104, 31381-31387, (1999)

12. Cloud to ground lightning flash characteristics in southeastern Brazil for 1992-1993 summer season, O. Pinto Jr, R.B.B. Gin, I.R.C.A. Pinto, O. Mendes Jr., Jose H. Diniz and Andre M. Carvalho, J. Geophys. Res., 101, 29,627-29,635 (1999)

13. A Re-examination of the Peak Current Calibration of the National Lightning Detection Network, V.P. Idone, A. B. Saljoughy, R. W. Henderson, P. Kmoore, R. B. Pyle, J. Geophys. Res., 98, 18,32318,332, (1993)

14. Measurements of lightning peak currents in the first return stroke of negative cloud to ground flashes, A.B. Weerasekera, D.U.J. Sonnadara, I.M.K. Fernando, T.R. Ariyaratne, J. P. Liyanage (unpublished) 